\title{
Chapter 6 \\ Capability in Research on Cognition and Well-being in Ageing and Retirement
}

\author{
Boo Johansson, Anne Ingeborg Berg, Pär Bjälkebring, \\ Marcus Praetorius Björk, Yvonne Brehmer, Sandra Buratti, \\ Isabelle Hansson, Linda Hassing, Georg Henning, Marie Kivi, Stefanie König, \\ Magnus Lindwall, Sindre Rolstad, Johan Skoog, Valgeir Thorvaldsson, \\ and Linn Elena Zulka
}

Capability is broadly defined as an individual's ability to perform actions in order to reach their own valued goals (Sen, 1985). The actual and observed capabilities are, however, more or less complex products, conditioned and influenced by numerous factors at the macro, meso and micro levels. The macro-level includes societal factors such as laws and regulations, pension systems, healthcare and social support systems. The meso-level includes dimensions of community involvement, social integration and networks, and the workplace and related retirement conditions. The micro-level is represented by individual factors, such as cognitive, mental and physical health. The main research focus within the ADA-Gero research group is on change and continuity at the individual or micro-level, although based on an understanding of the roles and influences of many macro- and meso-related circumstances.

Psychology is the science of brain and behaviour in which we as researchers explore the fundamental mechanisms involved in various mental processes, as well as personality dimensions that enable us to master challenges and the environment differently. The specific research questions addressed in the psychology of ageing are: how and why do developmental trajectories unfold in a certain manner with

\footnotetext{
B. Johansson $(\bowtie) \cdot$ A. I. Berg $\cdot$ P. Bjälkebring $\cdot$ M. Praetorius Björk $\cdot$ Y. Brehmer $\cdot$ S. Buratti I. Hansson · L. Hassing · G. Henning · M. Kivi · S. König · M. Lindwall · S. Rolstad

J. Skoog · V. Thorvaldsson · L. Elena Zulka

Department of Psychology, University of Gothenburg, Gothenburg, Sweden

Centre for Ageing and Health - AgeCap, University of Gothenburg,

Gothenburg, Sweden

e-mail: boo.johansson@psy.gu.se; anne.berg@psy.gu.se; pop-par.bjalkebring@psy.gu.se; marcus.praetorius.bjork@vgregion.se; y.brehmer@tilburguniversity.edu; sandra.buratti@psy.gu.se; isabelle.hansson@psy.gu.se; linda.hassing@psy.gu.se; georg.henning@psy.gu.se; marie.kivi@psy.gu.se; stefanie.konig@psy.gu.se; magnus.lindwall@gu.se; sindre.rolstad@neuro.gu.se; johan.skoog@psy.gu.se; valgeir.thorvaldsson@psy.gu.se; linn.zulka@psy.gu.se
} 
increasing age, and especially in older age? Based on a life-span perspective, we examine whether observed outcomes represent behavioural continuity, fundamental neurobiological ageing or disease-related changes. In this respect, the outcomes are seen as the products of a lifelong interplay between genetic and environmental influences. This makes it necessary to consider how the societal and historical contexts tend to influence individual ageing and outcomes in cohorts exposed to similar or non-shared environments.

\subsection{Capability and Cognition}

At the micro-level, the orchestration of several specialised cognitive abilities contributes to the overall cognitive capacity required for efficient environmental interaction, adaption and well-being. These cognitive abilities include, among others: perception, attention, processing speed, spatial orientation, language, memory processes, logical reasoning, decision-making and cognitive flexibility.

Cognitive ageing may not only alter older adults' ability to respond to and perform cognitively demanding tasks and operations, but may also change the ways in which individuals perceive and master cognitive tasks and demands. Fluid abilities refer to those cognitive processes that are typically used to solve novel challenges that are relatively independent of previous knowledge and acquired facts, and these generally show a decline after age 60-70 (Rönnlund et al., 2005). Our abilities to engage in solving tasks that require acquired knowledge and skills, also known as crystallised intelligence, are less affected and remain better preserved in later life (Thorvaldsson et al., 2006).

The probability of decline and compromised cognition unfortunately increases in later life, which may jeopardise older adults' ability to function in everyday life, and not only in a laboratory setting. Apart from normative age-related changes, a more compromised cognition is mainly produced by dementia disorders (Thorvaldsson et al., 2011) and other age-related diseases affecting the brain's integrity. Our own, as well as societal, expectations of cognitive ageing are also important (Robertson et al., 2016). Efforts to prevent cognitive decline and the identification of factors that can protect and promote preserved cognitive functioning are therefore important research targets in cognitive ageing research. In this context, the importance of lifestyle (e.g., physical activity, a healthy diet, no tobacco or alcohol use) and a stimulating environment (enrichment) is often stressed (e.g., Hassing, 2018; Hertzog et al., 2009; Lindwall et al., 2012). Intact cognition represents a core component for reaching personally valued goals, but also for generating and prioritising such goals. In this respect, cognitive abilities are also crucial for mastering many environmental demands at the meso- and macro-levels, as well as for coping with one's own decremental changes in body and brain, whether produced by disease processes or normative age-related changes.

A core idea in current cognitive ageing research is that ageing and cognitive capabilities need to be studied using research designs that allow analyses of 
between-person differences in within-person changes. Longitudinal designs are required to distinguish between-person (i.e., how an individual differs from others) and within-person variability (i.e., how an individual changes over time relative to his/her previous values and performance). In multidisciplinary longitudinal studies based on representative samples, like the $\mathrm{H} 70$ research programme, we have opportunities to study cognitive functioning at the population level, manifested as aggregated change or preserved functioning at the individual level. In addition, such a research programme allows us to study how observed outcomes are associated with previous lifespan influences, as well as with current health and socio-cultural conditions.

Our lives, and consequently our ageing, are always embedded in a historical context. Lifespan influences and exposures can differ substantially across generations. Comparisons of cognitive trajectories for various birth cohorts generally show superior performance levels in later-born cohorts (Rönnlund et al., 2013; Schaie \& Strother, 1968). The reasons for this improvement have been ascribed to multiple factors, including better nutrition (Lynn, 1998) and a more extended education (Rönnlund \& Nilsson, 2009). Our own and other studies, however, indicate a more marked decline, although from a higher level, in later birth cohorts, even for relatively simple tasks, requiring people to perceive, identify and then react and respond as quickly as possible (see Fig. 6.1; Gerstorf et al., 2011; Karlsson et al., 2015; Thorvaldsson et al., 2017).

An increasingly important focus in cognitive ageing research is on strategies to promote active and successful cognitive ageing and on the use of potentially compensatory strategies to master and cope with compromised abilities. These efforts are directly in line with the aim of improving the capabilities of older adults. Studies on brain plasticity during ageing provide support for old ideas concerning the "use it or lose it hypothesis' (Bielak, 2010; Salthouse, 2006), with various mental exercises and activity engagements seeming to partly counteract age-related cognitive decline and the risk of later dementia.

The cognitive reserve hypothesis (Stern, 2002) represents another important conceptual framework for research on cognitive ageing in its attempt to account for the incongruence between brain pathology/damage and its functional and clinical manifestations. Findings of weak relationships between neuronal brain damage and functional outcomes are attributed to differences in brain resilience and the abilities to use compensatory strategies and pre-existing cognitive networks to cope with cognitive challenges (Rolstad et al., 2009). Experiences across the lifespan, such as educational, occupational and recreational attainment (Hassing, 2017), seem to enhance cognitive reserves and improve our ability to better withstand age-related cognitive decline due to compromised brain functioning.

According to the cognitive reserve hypothesis, there is a potential to counteract age-related cognitive decline. An enriched environment with cognitive demands that match personal preferences, including extended work-related cognitive stimulation (i.e., working to a greater age or by promoting participation in bridge employment; and/or voluntary work) may mitigate decline (Mitchell et al., 2012). With between-person differences in mind, it should be noted that certain types of 


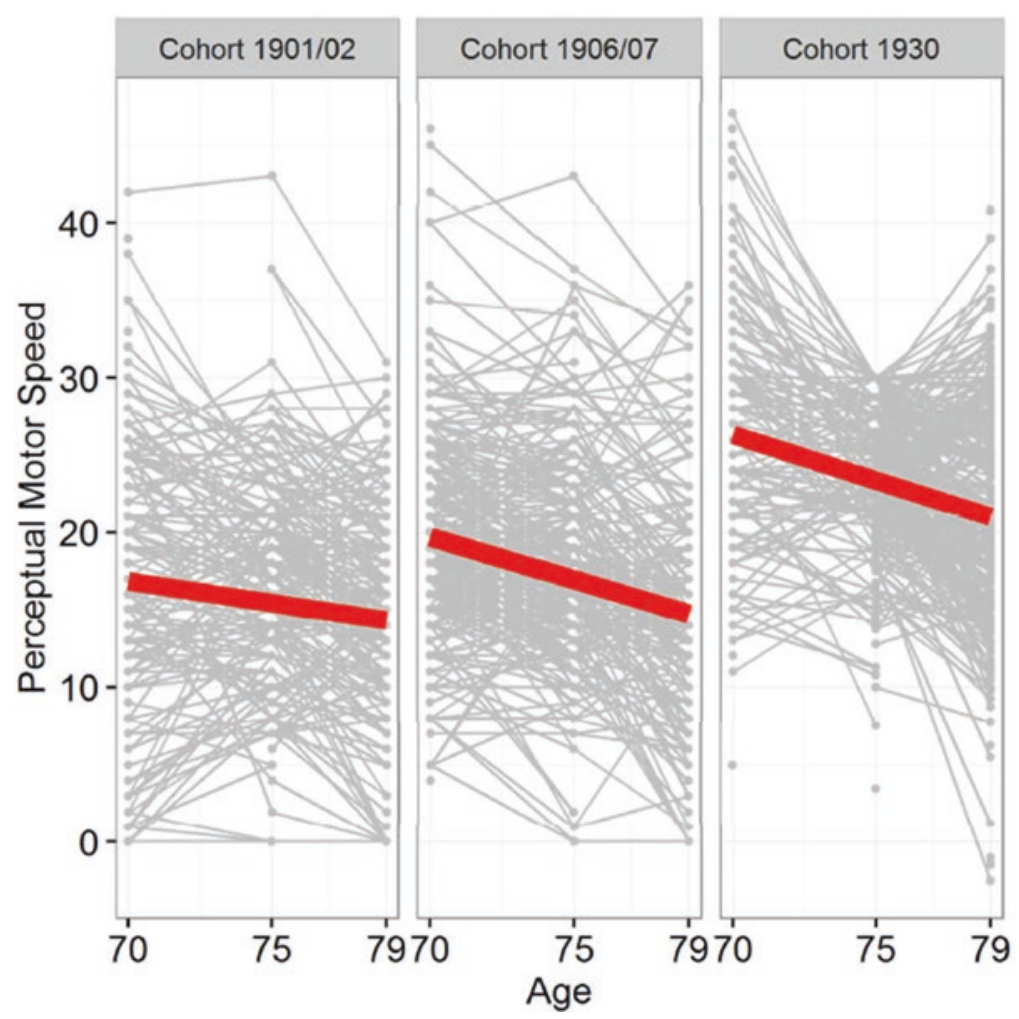

Fig. 6.1 Examples of raw score trajectories for a perceptual motor speed performance in cohorts born 1901/02, 1906/07 and 1930 and examined at ages 70, 75 and 79 in the H70 study. The red lines refer to the estimated average change trajectories (Thorvaldsson et al., 2017)

cognitive stimulation might not be feasible or even possible for everyone. For example, the possibility of bridge employment would not only depend on external circumstances (e.g., company employer), but also on the individual possessing sufficient cognitive abilities to take part in the planning and learning requirements associated with the position (Stafford et al., 2017). In cases like these, the individual's actual freedom of choice becomes important. Freedom of choice is a central aspect of Sen's capability model, along with available resources and conversion factors (Sen, 1992). More specifically, freedom of choice entails the possibility to realise goals that a person has reason to value. However, compromised cognitive abilities are likely to delimit the number of potential choices. For example, continuing employment beyond retirement age is unlikely to be offered to individuals lacking the cognitive ability to adapt to changing needs. In this context, education and lifelong learning have important roles to play in enhancing cognitive reserves and flexibility, which in turn can promote the capacity to counteract detrimental agerelated brain changes. Although education does not have a direct influence on cognitive ageing, recent studies suggest that it affects overall health behaviour and the 
socioeconomic conditions related to a more active and successful cognitive ageing (Clouston et al., 2015). In this respect, preserved or at least 'good enough' cognitive health becomes important for realising capability in old age.

\subsection{Capability and Subjective Well-being}

At the heart of the capability approach is the idea of individual agency and that each individual should have the right to live the life that she or he desires (Robeyns, 2005). Thus, the capability approach emphasises the individual's right to define personal goals and how these can best be reached. Capability can never be appropriately studied if the individual's own perspective is neglected because how capability is experienced serves as an indicator of the extent to which individuals feel that they actually have the life they desire. In this respect, capability is closely related to subjective well-being, and more specifically to life satisfaction, defined as the individual's evaluation of satisfaction with their life as a whole (Diener, 1984).

Subjective well-being is a central indicator of psychological health and vitality in late life (Smith \& Ryan, 2015), and it serves as an important predictor of future health status and longevity (Diener \& Chan, 2011). Subjective evaluations of life are relevant within the capability approach because they include judgements about the current life situation relative to the ideal (Schimmack et al., 2002), and therefore capture the discrepancy between perceived and anticipated conditions (Diener et al., 1998). Research has demonstrated that numerous individual and situational factors contribute to individual differences in subjective well-being (e.g., Berg et al., 2006) but also that life satisfaction tends to vary systematically with increasing age (Diener, 2013). From an adult developmental and ageing perspective, people generally seem to become more satisfied with their lives during the period from their $40 \mathrm{~s}$ until their early 70s, when life satisfaction peaks and thereafter declines (Baird et al., 2010).

The fact that happiness increases over the lifespan at the same time as the individual is more likely to be facing age-related declines in functional capacities is generally referred to as the paradox of well-being (e.g., Mroczek \& Kolarz, 1998). The explanations for these findings include an increase in adaptive capacity over the lifespan (i.e., the selection, optimisation and compensation (SOC) model; Baltes, 1997) and aspects of age-related maturation and improved emotional regulation (i.e., the socioemotional selectivity theory (SST); Carstensen et al., 2003). Alternative explanations include age-related differences in the preference for emotional arousal, suggesting that older adults are more likely to prefer satisfaction over intense sensation (Bjälkebring et al., 2015). The somewhat contradictory finding that well-being seems to increase over the life-course implies that psychological factors such as adaptive abilities and emotional regulation are key mechanisms for successful ageing. Lifespan developmental processes relating to psychological health and well-being may in this sense contribute to counterbalancing ageingrelated experiences of decline in functional capacities. 
The capability approach suggests that available resources represent necessary preconditions for the potential to perform actions and reach valued goals, but that many other circumstances can influence the ability to convert these resources into the functions needed to reach a specific goal (Robeyns, 2006). Research on subjective well-being demonstrates that the availability of resources, as well as the individual's own perception of these resources, is considered when people assess their own well-being (Diener, 2009; Heller et al., 2004). This means that objective circumstances, as well as individual factors and attributes are all of relevance for understanding individual differences in subjective well-being in late adulthood. Our own findings show that individual characteristics such as personality and perceptions of control are generally better predictors of life satisfaction among older adults, compared with objective circumstances such as income, health status or quantity of social relations (Berg et al., 2006; Berg et al., 2011; Berg et al., 2009; Hansson et al., 2018a, b; Henning et al., 2017).

In a recent study on subjective memory, an important marker of one's own perceived cognition related to well-being, in which a sample of men responded to the same questionnaire at age 40, and then 30 years later at age 70 , we found that those who reported better overall health and less anxiety also experienced less memory decline up to age 70. Higher stress and depression at age 70, however, were associated with worse subjective memory appearing as early as age 40 . The correlation between an overall memory factor at ages 40 and 70 was 0.58 , while the correlation between the memory factor at age 70 and retrospective ratings at age 40 was as high as 0.87 . These findings suggest that subjective memory is quite consistent, and that we are inclined to preserve a continuity of our own memory functioning over the adult lifespan (Johansson et al., 2020).

Personality, conventionally defined as consistent patterns of individual differences in thoughts, feelings and behaviours, is assumed to influence subjective wellbeing through its relevance for how people view and evaluate their lives and opportunities (Lucas \& Diener, 2009). Among the Big Five personality characteristics: extraversion, agreeableness, conscientiousness, neuroticism and openness (Goldberg, 1993), extraversion and neuroticism constitute the strongest and most reliable predictors of subjective well-being. Relatively higher levels of extraversion and lower levels of neuroticism are associated with higher satisfaction with life (Lucas \& Diener, 2009). High scores on extraversion are characterised by sociability, talkativeness and excitability, and a tendency to view life in optimistic terms and experience frequent positive emotions (Costa \& McCrae, 1980). High scores on neuroticism, on the other hand, are associated with a tendency to experience negative emotions, such as anger, anxiety and depression. Individuals who score highly on neuroticism are also more emotionally unstable in terms of having frequent mood swings, high irritability and stronger reactions to stress, which are assumed to negatively influence life evaluations (Costa \& McCrae, 1980). Research suggests that personality can have a direct impact on life evaluations, but also an indirect effect through its relevance for how a person reacts to and copes with various life challenges (Heller et al., 2004). Our own research shows that individuals with higher levels of extraversion are more likely to report higher satisfaction with life, 
partially because of a higher perceived resource capability, but also due to an increased probability of building and maintaining resources (Hansson et al., 2019). Individuals with higher scores on neuroticism, on the other hand, are more likely to report lower life satisfaction due to lower perceived resource capability, but also due to an increased vulnerability to resource loss during times of major life events, such as retirement (Hansson et al., 2019).

The capability approach represents a broad theoretical framework that helps us gain a better understanding of the many mechanisms that are involved in determining an individual's capability. The capability framework acknowledges that multiple individual and contextual factors influence the availability of important resources, but also the extent to which an individual can benefit from and convert these resources into the actions needed to achieve a specific goal. In this sense, the capability approach corresponds well with present knowledge about which factors are of relevance for how we view and evaluate our current life situation and overall functioning. We argue, however, that resources and conversion factors are not easily separable, but instead represent parallel processes that simultaneously influence each other. Personality, for instance, can serve as a resource (e.g., extraversion is a key resource in social activities) at the same time as it may influence the ability to use and benefit from other resources (e.g., social participation contributes to stimulating cognitive functions). It is therefore necessary to recognise that psychological resources, such as certain personality characteristics, are likely to influence an individual's capability through its relevance to the availability of resources, as well as the ability to convert these resources into desired functions.

Sleep constitutes a major prerequisite for preserved capability in cognition and well-being throughout life. During ageing, however, we can often observe changes in sleep quantity and quality. People tend to report more early awakenings, increased sleep onset latency, more day-time naps and shorter sleep duration and may therefore show a reduced sleep efficiency, which is defined as the ratio of time spent asleep compared to the amount of time spent in bed (Skoog et al. 2019; AncoliIsrael, 2009; Cajochen et al., 2006; Roepke \& Ancoli-Israel, 2010). In a metaanalysis, Ohayon and colleagues (2004) conclude that total sleep time, sleep efficiency, and the proportion of slow-wave and rapid eye movement sleep decrease with age, while the number of awakenings after sleep onset, as well as sleep latency and proportions of stage 1 and stage 2 sleep tend to increase. Given that sleep affects memory consolidation and emotional well-being, it also represents a significant marker of health and overall functioning. For example, Liu and collaborators (2020) found that periodic sleep disruption for only one night led to impaired functioning of older adults' sleep-related memory consolidation. Sleep patterns may also change over time, not only with age. In a longitudinal study of the prevalence of insomnia, in which we compared and followed two birth cohorts of 70-year-olds born 30 years apart, we found that the prevalence of insomnia was lower in the later birth cohort (about 32\% in the birth cohort born in 1901-07, compared with 16\% in those born in 1930). Interestingly, the prevalence of insomnia increased from age 70 to 79 only in the later cohort, but at age 79 the prevalence was similar in both cohorts (32\%). Insomnia was more common in women, although the sex difference was less 
pronounced in the later-born birth cohort. Poor sleep has also been associated with a higher incidence of dementia. In another study, we found that early-morning awakenings with an inability to return to sleep, i.e. terminal insomnia, and long sleep duration at age 70 was related to an increased risk of developing dementia (Sindi et al., 2018). A better understanding of the associations between sleep, cognitive decline and well-being is essential in order to design public health and personoriented interventions that can improve health and wellbeing, and thereby capability, in older adults.

\subsection{Cognition and Well-being in the Social Context of Retirement}

Retirement marks a significant life event that is often considered the societally defined entrance into 'old age'. Our research team is currently involved in a research programme focusing on older adults' transition to retirement, the HEARTs study (HEalth, Ageing, and Retirement Transition in Sweden; see Lindwall et al., 2017). In this programme, we longitudinally investigate outcomes of the transition to retirement, with a focus on conditions before and after the retirement event. This allows us to investigate whether retirement expectations and life-course experiences affect overall health, cognition and/or well-being. Although our focus is on individual trajectories, these micro-level analyses are conducted in the context of mesoand macro-level conditions. Thus, cognitive health and well-being are considered within the social context in which societal norms and legislation on labour-market participation are confronted with work/life requirements, job demands and individual retirement preferences.

The rationale for implementing the overarching capability framework in research on retirement transitions is that it broadens the perspective beyond that of previously limited accounts focusing mainly on 'work ability' or 'employability'. What an individual can or cannot do at any given time is a reflection of resources or capacities, and whether available resources can be converted into a desired function; for example, preferences to continue working or to retire. Choice is crucial in the capability approach. In particular, the perception of choice and whether an individual feels that he or she has autonomy and 'ownership' of their life, no matter what the actual situation of choice might be.

Being able to work in terms of overall good physical and cognitive health does not necessarily lead to a prolonged working life if the individual is unable to find employment or keep their job (e.g., low employability). Conversely, individuals who in fact have low physical and cognitive capabilities to continue at work may experience that they are unable to exit working life due to the financial consequences (e.g., low pension benefits) or pension-system regulations (e.g., a guaranteed pension at age 65). The individual's motivation to continue working or to retire is crucial and constitutes the key link to capability because it directly relates to the 
meaning of choice and individual preferences for desired outcomes. Research on multidimensional work motivation (e.g., Gagné, 2014) highlights the difference between autonomous motivation (i.e., actions being performed with a 'full sense of willingness, volition, and choice'; Deci et al., 2017: 20), controlled motivation (i.e. motivation driven by external factors) and amotivation (i.e. lack of any motivation). Our results from the HEARTS study show that people who are more autonomously motivated to work also seem to be more likely to continue working in retirement. Those with low autonomous motivation experience more autonomy after they fully retire. These results support the idea that being able to pursue the activities one values leads to greater well-being (Henning et al., 2019).

The effects of retirement on capability differ most clearly among individuals, given multiple background characteristics and current overall situation. In the HEARTS study, we argue that the retirement transition can serve as a 'lens' (see Fig. 6.2). It can either amplify or mitigate social differences in cognition and wellbeing, based on factors such as education, occupation and income. In this respect, retirement may have different effects across social groups (König et al., 2018). For example, at the time of retirement we could expect different levels of cognitive functioning between people retiring from jobs characterised by lower versus higher cognitive stimulation, in addition to differences in education and socioeconomic status. Retirement may also trigger adaptations in cognitive functioning. In a recent literature review of longitudinal studies, we revealed mixed evidence for an association between cognition and retirement (Zulka et al., 2019). Among the 20 reviewed studies, nine included prior work demands (e.g. cognitive stimulation at the workplace) as a potential moderator of the relationship between cognitive performance and retirement. A synthesis of these findings provides support for the idea that prior work demands can indeed affect the association. Thus, while retirement seems to be beneficial for blue-collar workers (or retirees from physically demanding jobs), the evidence for white-collar workers (or retirees from cognitively demanding jobs) was less conclusive, with both cognitive improvements and decline being reported

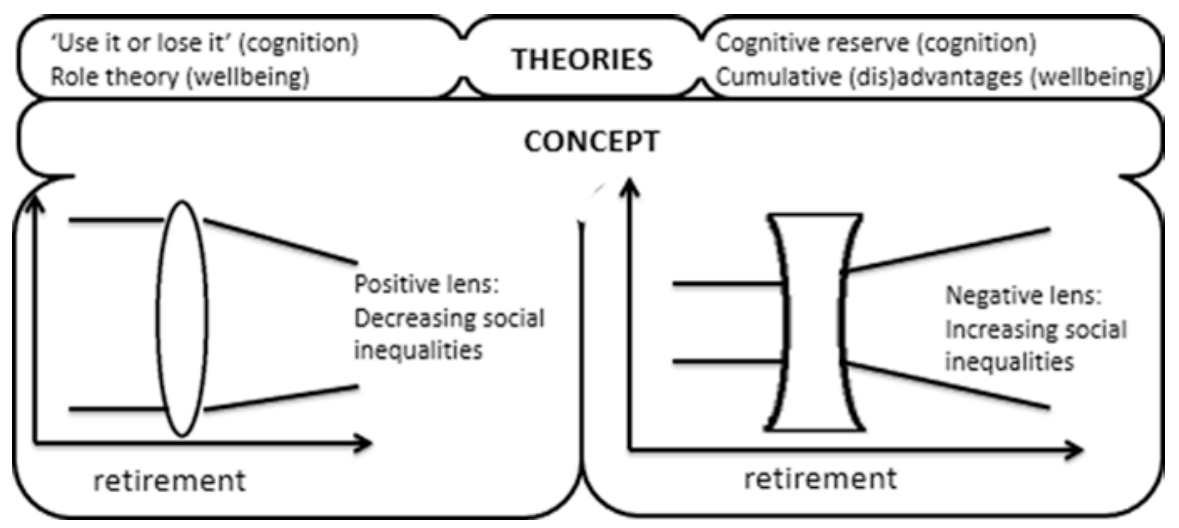

Fig. 6.2 The retirement transitions as a lens for social inequalities (König et al., 2018) 
(Zulka et al., 2019). In the HEARTS study, we recently examined the potential impact of prior cognitive work demands as a moderator in the retirement transition. The analyses did not provide support for a significant effect over a more restricted period after the retirement event (Zulka et al., submitted).

Although the above model focuses on outcomes in terms of cognition and wellbeing, it also highlights other, heterogeneous effects of retirement on capability. The lens perspective is closely linked to the life-course perspective in which multiple factors unfold over the entire lifespan, which contributes to differential lens effects. For example, in HEARTS we found that differences in cognitive functioning due to level of education was smaller in the group of people who had retired compared with those still in the workforce. This result supports the notion of a positive lens (mitigating) effect of retirement on cognitive functioning. However, the opposite result was found for well-being; educational differences in well-being were larger in retirees compared to people who were still working, supporting the notion of a negative lens (amplifying) effect for well-being (König et al., 2018).

Further studies will be conducted to specifically examine the proposed risk of 'a mental and cognitive retirement', ideas largely based on the 'use it or lose it' hypothesis in which retirement is also seen as a major risk of imposing lifestyle changes, with a reduction in cognitive engagement and stimulation. However, cognition and psychological well-being are crucial, as both predictors and outcomes when investigating adaptive processes in the retirement transition. Well-being reflects the achievement of individual preferences, which makes it a core component of defining 'successful retirement' at the individual level. 'Good enough cognition' is, however, required when coping with the challenges associated with this major transition and forming a good life as a retiree.

\subsection{Capability in the Context of the COVID-19 Pandemic}

The current worldwide COVID-19 pandemic represents a significant threat to overall public health, particularly among vulnerable risk groups. Many countries have enacted a general lockdown, whereas the Swedish policy largely relies on voluntary preventative behaviour and fewer mandatory restrictions, apart from a specific recommendation for social distancing and 'shelter in place' for those aged 70 and older. The overarching goal was to protect older adults, who are considered more vulnerable to a viral infection.

The HEARTS study, with its longitudinal design and annual measurements during the years 2015-2020, provides unique opportunities to investigate the impact of COVID-19 on various aspects of health and well-being. In the 2020 wave, we included a new set of questions to capture levels of worry, risk perception and social distancing in response to the COVID-19 pandemic. Findings based on data collected during one week in the early days of the pandemic (26 March to 2 April 2020 for those aged 65-71) showed that $45 \%$ reported high levels of worry about their own, or loved ones', health, and $42 \%$ perceived a high risk of being infected by the 
novel coronavirus (Kivi et al., 2020). A substantial proportion (70\%) also worried about adverse effects on social structures and the world economy and $86 \%$ perceived a high risk of negative consequences for public health and welfare. Individuals aged 70 and above (defined as a risk group by The Public Health Agency of Sweden) reported avoiding close physical contact with others to a larger extent (79\%) than those in the age range 65-69 (69\%), and they also perceived the risk of infection as lower (35\% and $46 \%$, respectively). Individuals in the age group 70-71 additionally reported less worry about the impact of COVID-19 on their personal finances (20\%) compared to those aged 65-69 (28\%). Preliminary analyses based on the full wave of data collection in $2020(\mathrm{~N}=3914)$ showed an average increase in worry about personal (or loved ones') health and an increase in the degree of social distancing between March and May 2020. The previously observed differences in levels of worry about personal finances, the degree of social distancing and the perceived risk of infection between individuals above and below the age of 70 were also mirrored in these analyses.

We further examined changes in four domains of well-being (life satisfaction, financial satisfaction, self-rated health and loneliness) compared to previous years (2015-2020). The findings showed an average decline in self-rated health from 2015 (age 60-66) to 2019 (age 64-70), but an increase in 2020 (age 65-71; Kivi et al., 2020). Financial satisfaction remained stable between 2015 and 2020 but increased in 2020, and life satisfaction showed an average increase between 2015 and 2019, with no deviation in this trend in 2020. Loneliness remained relatively stable between the years 2015 and 2020.

Preliminary analyses based on data from the period March to May (weeks 13-20) 2020 mirrored the effects for life satisfaction, financial satisfaction and self-rated health but, in contrast to the findings in the early days of the COVID-19 pandemic, we found an increase in loneliness compared to previous years. The increase in loneliness was also greater for individuals who responded to the survey later in the spring of 2020. Analyses of differences between individuals above and below the age of 70 further suggest that the positive changes in well-being are more pronounced in the age group 65-69, while individuals above the age of 70 who responded to the survey later in the spring of 2020 reported slightly lower levels of well-being compared to 2019.

The somewhat unexpected finding that older adults rated their well-being during the early phase of the COVID-19 pandemic as highly as, or even higher than, they did in previous years may reflect the fact that older adults refuse to identify themselves as a risk group. They rather tend to view themselves as individuals who are just as capable as others to assess risks and make informed decisions. The fact that Sweden, in contrast to many other countries, did not impose a national lockdown may also contribute to explaining why we found relatively few negative effects on well-being. Another possible explanation is the notion of contrasts, i.e., that the reference point against which the assessment is made has changed. In the context of COVID-19, assessments of personal well-being are likely to be formed in relation to many other possible risks and effects of the pandemic. Circumstances that seemed 
less satisfying before the pandemic may therefore be given less weight when possible consequences related to COVID-19 are taken into account.

In conclusion, and in contrast to many ageist assumptions about frailty and inability in old age, our findings suggest that the agency and capability of older adults to perform actions and reach valued goals persist, even during a pandemic. It is important to note, however, that the restrictions imposed on older adults are likely to have contributed to the observed increase in loneliness. The specific restrictions imposed on individuals aged 70 and above may also explain why the positive effects were more pronounced in the age group 65-69. The authorities should therefore consider the risk of compromised capability among older adults due to age-specific restrictions during times of pandemic.

\subsubsection{In Sum}

The core ideas of the capability approach are influencing ongoing and planned research on cognition, subjective well-being and retirement conducted by members of the ADA-Gero research team. From our psychological perspective, the approach emphasises the need to contextualise the micro-level perspective on ageing individuals' cognition and well-being within the meso- and macro-level influences that affect the realisation of personal goals. This means that we certainly realise that ageing trajectories are always embedded in a specific historical and sociocultural context in which societal systems regulate brain-behaviour relationships according to the age of their members. The capability approach constitutes a theoretical framework that is well suited to a broader understanding of the factors and mechanisms involved in shaping age-related developmental and psychological processes across the life course, and especially in late life.

\section{References}

Ancoli-Israel, S. (2009). Sleep and its disorders in aging populations. Sleep Medicine,, 10(Suppl 1), S7-S11. https://doi.org/10.1016/j.sleep.2009.07.004.

Baird, B. M., Lucas, R. E., \& Donnellan, M. B. (2010). Life satisfaction across the lifespan: Findings from two nationally representative panel studies. Social Indicators Research, 99, 183-203. https://doi.org/10.1007/s11205-010-9584-9

Baltes, P. (1997). On the incomplete architecture of human ontogeny: Selection, optimization, and compensation as foundation of developmental theory. American Psychologist, 52, 366-380. https://doi.org/10.1037/0003-066X.52.4.366

Berg, A. I., Hassing, L. B., McClearn, G. E., \& Johansson, B. (2006). What matters for life satisfaction in the oldest-old? Ageing and Mental Health, 10, 257-264. https://doi. org/10.1080/13607860500409435

Berg, A. I., Hoffman, L., Hassing, L. B., McClearn, G. E., \& Johansson, B. (2009). What matters, and what matters most, for change in life satisfaction in the oldest-old? A study over 
6 years among individuals 80+. Ageing and Mental Health, 13, 191-201. https://doi. org/10.1080/13607860802342227

Berg, A. I., Hassing, L. B., Thorvaldsson, V., \& Johansson, B. (2011). Personality and personal control make a difference for life satisfaction in the oldest-old: Findings in a longitudinal population-based study of individuals 80 and older. European Journal of Ageing, 8, 13-20. https://doi.org/10.1007/s10433-011-0181-9

Bielak, A. A. M. (2010). How can we not 'lose it' if we still don't understand how to 'use it'? Unanswered questions about the influence of activity participation on cognitive performance in older age: A mini-review. Gerontology, 56, 507-519. https://doi.org/10.1159/000264918

Bjälkebring, P., Västfjäll, D., \& Johansson, B. (2015). Happiness and arousal: Framing happiness as arousing results in lower happiness ratings for older adults. Frontiers in Psychology, 6, 706. https://doi.org/10.3389/fpsyg.2015.00706

Cajochen, C., Munch, M., Knoblauch, V., Blatter, K., \& Wirz-Justice, A. (2006). Age-related changes in the circadian and homeostatic regulation of human sleep. Chronobiology International, 23(1-2), 461-474. https://doi.org/10.1080/07420520500545813

Carstensen, L. L., Fung, H. H., \& Charles, S. T. (2003). Socioemotional selectivity theory and the regulation of emotion in the second half of life. Motivation and Emotion, 27, 103-123. https:// doi.org/10.1023/A:1024569803230

Clouston, S. A., Glymour, M., \& Terrera, G. M. (2015). Educational inequalities in ageing-related declines in fluid cognition and the onset of cognitive pathology. Alzheimers Dement (Amst), 1, 303-310. https://doi.org/10.1016/j.dadm.2015.06.001

Costa, P. T., \& McCrae, R. R. (1980). Influence of extraversion and neuroticism on subjective wellbeing: Happy and unhappy people. Journal of Personality and Social Psychology, 38, 668-678. https://doi.org/10.1037/0022-3514.38.4.668

Deci, E. L., Olafsen, A. H., \& Ryan, R. M. (2017). Self-determination theory in work organizations: The state of a science. Annual Review of Organizational Psychology and Organizational Behavior, 4, 19-43. https://doi.org/10.1146/annurev-orgpsych-032516-113108

Diener, E. (1984). Subjective Well-being. Psychological Bulletin, 95, 542-575. https://doi. org/10.1037/0033-2909.95.3.542

Diener, E. (2009). The science of Well-being: The collected works of Ed Diener. Springer.

Diener, E. (2013). The remarkable changes in the science of subjective well-being. Perspectives on Psychological Science, 8, 663-666. https://doi.org/10.1177/1745691613507583

Diener, E., \& Chan, M. Y. (2011). Happy people live longer: Subjective well-being contributes to health and longevity. Applied Psychology: Health and Well-Being, 3, 1-43. https://doi. org/10.1037/e675972011-001

Diener, E., Sapyta, J., \& Suh, E. (1998). Subjective well-being is essential to well-being. Psychological Inquiry, 9, 33-37. https://doi.org/10.1207/s15327965pli0901_3

Gagné, M. (2014). The Oxford handbook of work engagement, motivation, and self-determination theory. Oxford Library of Psychology.

Gerstorf, D., Ram, N., Hoppman, C., Willis, S. L., \& Schaie, K. W. (2011). Cohort differences in cognitive ageing and terminal decline in the Seattle Longitudinal Study. Developmental Psychology, 47, 1026-1041. https://doi.org/10.1037/a0023426

Goldberg, L. R. (1993). The structure of phenotypic personality traits. The American Psychologist, 48, 26-34. https://doi.org/10.1037/0003-066x.48.1.26

Hansson, I., Buratti, S., Johansson, B., \& Berg, A. I. (2018a). Beyond health and economy: Resource interactions in retirement adjustment. Ageing and Mental Health, 23, 1546-1554. https://doi.org/10.1080/13607863.2018.1506745

Hansson, I., Buratti, S., Thorvaldsson, V., Johansson, B., \& Berg, A. I. (2018b). Changes in life satisfaction in the retirement transition: Interaction effects of transition type and individual resources. Work, Ageing and Retirement, 4, 352-366. https://doi.org/10.1093/worker/wax025

Hansson, I., Henning, G., Buratti, S., Lindwall, M., Kivi, M., Johansson, B., \& Berg, A. I. (2019). The role of personality in retirement adjustment: Longitudinal evidence for the effects on life satisfaction. Journal of Personality. https://doi.org/10.1111/jopy.12516 
Hassing, L. B. (2017). Gender differences in the association between leisure activity in adulthood and cognitive function in old age: A prospective longitudinal population-based study. The Journals of Gerontology: Series B, gbx170. https://doi.org/10.1093/geronb/gbx170.

Hassing, L. B. (2018). Light alcohol consumption does not protect cognitive function: A longitudinal prospective study. Frontiers in Ageing Neuroscience. https://doi.org/10.3389/ fnagi.2018.00081

Heller, D., Watson, D., \& Ilies, R. (2004). The role of person versus situation in life satisfaction: A critical examination. Psychological Bulletin, 130, 574-600. https://doi. org/10.1037/0033-2909.130.4.574

Henning, G., Hansson, I., Berg, A. I., Lindwall, M., \& Johansson, B. (2017). The role of personality for subjective well-being in the retirement transition: Comparing variable-and person-oriented models. Personality and Individual Differences, 116, 385-392. https://doi.org/10.1016/j. paid.2017.05.017

Henning, G., Stenling, A., Tafvelin, S., Hansson, I., Kivi, M., Johansson, B., \& Lindwall, M. (2019). Preretirement work motivation and subsequent retirement adjustment: A self-determination theory perspective. Work, Ageing and Retirement, 5, 189-203. https://doi.org/10.1016/j. paid.2017.05.017

Hertzog, C., Kramer, A. F., Wilson, R. S., \& Lindenberger, U. (2009). Enrichment effects on adult cognitive development: Can the functional capacity of older adults be preserved and enhanced? Psychological Science in the Public Interest, 9, 1-65. https://doi.org/10.1093/workar/way017

Johansson, B., Praetorius Björk, M., \& Thorvaldsson, V. (2020). I rate my memory quite similar at age 40 and at age 70: Findings in a Swedish longitudinal study on subjective memory over a 30-year period. GeroPsych: The Journal of Gerontopsychology and Geriatric Psychiatry. Advance online publication. https://doi.org/10.1024/1662-9647/a000239

Karlsson, P., Thorvaldsson, V., Skoog, I., Gudmundsson, P., \& Johansson, B. (2015). Birth cohort differences in fluid cognition in old age: Comparisons of trends in levels and change trajectories over 30 years in three population-based samples. Psychology and Ageing, 30, 83-94. https://doi.org/10.1037/a0038643

Kivi, M., Hansson, I., \& Bjälkebring, P. (2020). Up and about: Older adults' well-being during the COVID-19 pandemic in a Swedish longitudinal study. The Journals of Gerontology. Series B, Psychological Sciences and Social Sciences. https://doi.org/10.1093/geronb/gbaa084

König, S., Lindwall, M., Henning, G., \& Johansson, B. (2018). Retirement as a lens for socioeconomic differences in cognition and well-being. Nordic Journal of Working Life Studies, 8, 63-80. https://doi.org/10.18291/njwls.v8i2.106155

Lindwall, M., Cimino, C. R., Gibbons, L. E., Mitchell, M. B., Benitez, A., Brown, C. L., et al. (2012). Dynamic associations of change in physical activity and change in cognitive function: Coordinated analyses of four longitudinal studies. Journal of Ageing Research. https:// doi.org/10.1155/2012/493598

Lindwall, M., Berg, A. I., Bjälkebring, P., Buratti, S., Hansson, I., Hassing, L., ... Johansson, B. (2017). Psychological health in the retirement transition: Rationale and first findings in the health, ageing and retirement transitions in Sweden (HEARTS) study. Frontiers in Psychology, 8, 1634. https://doi.org/10.3389/fpsyg.2017.01634

Liu, X., Peng, X., Peng, P., Li, L., Lei, X., \& Yu, J. (2020). The age differences of sleep disruption on mood states and memory performance. Aging \& Mental Health, 24(9), 1444-1451. https:// doi.org/10.1080/13607863.2019.1603286

Lucas, R. E., \& Diener, E. (2009). Personality and subjective wellbeing. In E. Diener (Ed.), The science of well-being: The collected works of Ed Diener (pp. 75-102). Springer.

Lynn, R. (1998). In support of the nutrition theory. In U. Neisser (Ed.), The rising curve: Longterm gains in $I Q$ and related measures (pp. 207-218). American Psychological Association.

Mitchell, M. B., Cimino, C. R., Benitez, A., Brown, C. L., Gibbons, L. E., Kennison, R. F., et al. (2012). Cognitively stimulating activities: Effects on cognition across four studies with up to 21 years of longitudinal data. Journal of Ageing Research. https://doi.org/10.1155/2012/461592 
Mroczek, D. K., \& Kolarz, C. M. (1998). The effect of age on positive and negative affect: A developmental perspective on happiness. Journal of Personality and Social Psychology, 75, 1333-1349. https://doi.org/10.1037/0022-3514.75.5.1333

Robertson, D. A., King-Kallimanis, B. L., \& Kenny, R. A. (2016). Negative perceptions of ageing predict longitudinal decline in cognitive function. Psychology and Ageing, 31, 71-81. https:// doi.org/10.1037/pag0000061

Robeyns, I. (2005). The capability approach: A theoretical survey. Journal of Human Development, 6, 93-117. https://doi.org/10.1080/146498805200034266

Robeyns, I. (2006). The capability approach in practice. Journal of Political Philosophy, 14, 351-376. https://doi.org/10.1111/j.1467-9760.2006.00263.x

Roepke, S. K., \& Ancoli-Israel, S. (2010). Sleep disorders in the elderly. The Indian Journal of Medical Research, 131, 302-310.

Rolstad, S., Nordlund, A., Eckerström, C., Gustavsson, M. H., \& Zetterberg, H. (2009). Biomarkers in relation to cognitive reserve in patients with mild cognitive impairment: Proof of concept. Dementia and Geriatric Cognitive Disorders, 27, 194-200. https://doi.org/10.1159/000203130

Rönnlund, M., \& Nilsson, L.-G. (2009). Flynn effects on sub-factors of episodic and semantic memory: Parallel gains over time and the same set of determining factors. Neuropsychologia, 47, 2174-2180. https://doi.org/10.1016/j.neuropsychologia.2008.11.007

Rönnlund, M., Nyberg, L., Bäckman, L., \& Nilsson, L.-G. (2005). Stability, growth, and decline in adult life span development of declarative memory: Cross-sectional and longitudinal data from a population-based study. Psychology and Ageing, 20, 3-18. https://doi. org/10.1037/0882-7974.20.1.3

Rönnlund, M., Carlstedt, B., Blomstedt, Y., Nilsson, L.-G., \& Weinehall, L. (2013). Secular trends in cognitive test performance: Swedish conscript data 1970:1993. Intelligence, 41, 19-24. https://doi.org/10.1016/j.intell.2012.10.001

Salthouse, T. A. (2006). Mental exercise and mental ageing: Evaluating the validity of the 'use it or lose it' hypothesis. Perspectives on Psychological Science, 1, 68-87. https://doi. org/10.1111/j.1745-6916.2006.00005.x

Schaie, K. W., \& Strother, C. R. (1968). The effect of time and cohort differences on the interpretation of age changes in cognitive behavior. Multivariate Behavioral Research, 3, 259-293. https://doi.org/10.1207/s15327906mbr0303_1

Schimmack, U., Diener, E., \& Oishi, S. (2002). Life-satisfaction is a momentary judgment and a stable personality characteristic: The use of chronically accessible and stable sources. Journal of Personality, 70, 345-384. https://doi.org/10.1111/1467-6494.05008

Sen, A. (1985). Commodities and capabilities. Elsevier Science Publishers B.V.

Sen, A. (1992). Inequality re-examined. Clarendon Press.

Sindi, S., Kåreholt, I., Johansson, L., Skoog, J., Sjöberg, L., Wang, H. X., ... Solomon, A. (2018). Sleep disturbances and dementia risk: A multicenter study. Alzheimer's \& Dementia, 14(10), 1235-1242. https://doi.org/10.1016/j.jalz.2018.05.012

Skoog, J., Jonsson, H., Sigstrom, R., Ostling, S., Falk, H., Waern, M., ... Johansson, B. (2019). Do later-born birth cohorts of septuagenarians sleep better? A prospective population-based study of two birth cohorts of 70-year-olds. Sleep, 42(1). https://doi.org/10.1093/sleep/zsy204

Smith, J. H., \& Ryan, L. (2015). Psychological vitality in the oldest old. In K. W. Schaie \& S. L. Willis (Eds.), Handbook of the psychology of ageing (8th ed., pp. 303-319). Elsevier.

Stafford, M., Cooper, R., Cadar, D., Carr, E., Murray, E., Richards, M., ... Kuh, D. (2017). Physical and cognitive capability in mid-adulthood as determinants of retirement and extended working life in a British cohort study. Scandinavian Journal of Work, Environment \& Health, 43, 15-23. https://doi.org/10.5271/sjweh.3589

Stern, Y. (2002). What is cognitive reserve? Theory and research application of the reserve concept. Journal of the International Neuropsychological Society, 8, 448-460. https://doi. org/10.1017/S1355617702813248 
Thorvaldsson, V., Hofer, S. M., Berg, S., \& Johansson, B. (2006). Effects of repeated testing in a longitudinal age-homogenous study of cognitive ageing. Journal of Gerontology: Psychological Sciences, 61, 348-354. https://doi.org/10.1093/geronb/61.6.P348

Thorvaldsson, V., MacDonald, S. W. S., Fratiglioni, L., Winblad, B., Kivipelto, M., Laukka, E. J., ... Bäckman, L. (2011). Onset and rate of cognitive change before dementia diagnosis: Findings from two Swedish population-based longitudinal studies. Journal of the International Neuropsychological Society, 17, 154-162. https://doi.org/10.1017/S1355617710001372

Thorvaldsson, V., Karlsson, P., Skoog, J., Skoog, I., \& Johansson, B. (2017). Better cognition in new birth cohorts of 70-year-olds, but greater decline thereafter. Journal of Gerontology: Psychological Sciences, 72, 16-24. https://doi.org/10.1093/geronb/gbw125

Zulka, L. E., Hansson, I., \& Hassing, L. (2019). Impact of retirement on cognitive function: A literature review. GeroPsych - The Journal of Gerontopsychology and Geriatric Psychiatry. https://doi.org/10.1024/1662-9647/a000215

Zulka, L. E., Hansson, I., Thorvaldsson, V., \& Hassing, L. (submitted). Cognitive functioning when retiring: Findings from a Swedish population-based longitudinal study.

Open Access This chapter is licensed under the terms of the Creative Commons Attribution 4.0 International License (http://creativecommons.org/licenses/by/4.0/), which permits use, sharing, adaptation, distribution and reproduction in any medium or format, as long as you give appropriate credit to the original author(s) and the source, provide a link to the Creative Commons license and indicate if changes were made.

The images or other third party material in this chapter are included in the chapter's Creative Commons license, unless indicated otherwise in a credit line to the material. If material is not included in the chapter's Creative Commons license and your intended use is not permitted by statutory regulation or exceeds the permitted use, you will need to obtain permission directly from the copyright holder. 